\title{
Association of parental factors and delayed dental care for children
}

SADJ November 2021, Vol. 76 No. 10 p607 - p612

NA Mukhari-Baloyi ${ }^{1}$, KJ Ramphoma ${ }^{2}$, MG Phalwane ${ }^{3}$, PD Motloba ${ }^{4}$

\section{ABSTRACT}

\section{Introduction}

There is a general perception that majority of parents delay seeking oral health care services for their children. However, the reasons for this health seeking behaviour and the related contributing factors are poorly understood.

\section{Aims}

To investigate the parental factors that influence delayed dental care for their children.

\section{Methodology}

A descriptive cross-sectional survey that was conducted at MEDUNSA Oral Health Centre and other oral health facilities within Tshwane oral health district. Parents of children 12 year and younger participated in the study.

\section{Results}

The average age of 350 parents and children in the study was $36.94( \pm 9.40)$ and $6.31( \pm 2.38)$ years respectively. Most parents were female 315 (90.0\%), unemployed 281 (80.3\%) and reached high school education 281 (80.3\%). The association between gender, age, employment and $\mathrm{dmft}$ with delayed dental treatment for children was not statistically significant. Parents considered acute medical conditions as urgent compared to dental pain and conditions $(\mathrm{OR}=1.27)$. Regular use of home remedies and medications exacerbated delayed dental visits for children, irrespective of the problem.

\section{Author affiliations:}

1. NA Mukhari-Baloyi: Department of Community Dentistry, University of Pretoria. ORCID Number: 0000-0002-4374-0186

2. KJ Ramphoma: Department of Community Dentistry, Sefako Makgatho Health Sciences University, ORCID Number: 0000-00019975-2912

3. MG Phalwane: Department of Community Dentistry, Sefako Makgatho Health Sciences University, ORCID Number: 0000-00022977-9092

4. PD Motloba: Department of Community Dentistry, Sefako Makgatho Health Sciences University. ORCID Number: 0000-00031379-7576

\section{Corresponding author:}

PD Motloba: Department of Community Dentistry, University of Pretoria. Email: pagollang.motloba@smu.ac.za

\section{Author contributions:}

1. NA Mukhari-Baloyi: $35 \%$ - research development and implementation, write-up, final review and editing

. KJ Ramphoma: $20 \% \%$ - write-up, final review and editing

3. MG Phalwane: $20 \% \%$ - write-up, final review and editing

4. PD Motloba: $25 \%$ data analysis, write-up, final review and editing

\section{Conclusion}

Parental attitude and perception of oral health contribute delayed dental visits by children. Majority of parents resorted to alternative remedies such as self-medication in managing children's oral health pain and conditions instead of seeking oral health care for their children.

\section{BACKGROUND}

Dental caries is the most prevalent condition among children', affecting 620 million (9\%) children globally. ${ }^{2}$ In South Africa, as many as $60 \%$ of children have dental caries of which $80 \%$ remain untreated indicating that South Africa has not achieved the National Department of Health goal to have at least 50\% of children under the age of 6 years being caries free. ${ }^{3} \mathrm{~A}$ large population of children are still experiencing a huge burden of untreated caries, which results in serious complications. The cost of delayed treatment of dental disease is exorbitant. ${ }^{4}$ The impact of dental caries includes, school absenteeism, learning difficulties among children and loss of income for parents due to work absenteeism. ${ }^{4}$ The lost productivity time is estimated to equal 52 million hours of work. ${ }^{5}$

Children are not responsible for their own health nor the identification of their health needs and care. It is the responsibility of parents or guardians to ensure that the rights of children to health care is realised. Therefore, delays in seeking dental care for any child is the failure of the parents or guardian to discharge their parental duties and responsibilities. Several individual and societal factors contribute to health seeking behaviour, utilisation of services or failure to access the needed services. Poor education, unemployment, young age, families with large number of children, and other systemic socio-economic barriers are factors associated with neglect and delays in dental visits for children. ${ }^{6,7}$ Parental oral health status, knowledge and perceptions are correlated to attitudes and behaviour towards health and oral health. ${ }^{8}$ There is a general misconception that dental conditions affecting children are not important and that dental extractions resolve majority of dental problems in children. ${ }^{9}$ Evidence suggests that children from lower income families have a higher prevalence of caries and of untreated oral disease and a lower tendency to visit the dentist. Children living under these socio-economic environments are prone to dental neglect owing to high barriers to access healthcare service.

The current study sought to explore the parental factors associated with delayed dental visits by children, which in the context of this study is viewed as inappropriate health seeking behaviour (HSB). 
Conceptual framework for the study

Variety of behavioural models have been adapted to explain patterns of health care utilisation or health seeking behaviour. ${ }^{10-13}$ According to these models, several factors are critical in predicting the likelihood of action or inaction by individuals in responding to health episodes. Personal and societal resources, culture and beliefs are amongst the most critical factors in healthcare seeking behaviour. ${ }^{12,14}$ The Andersen and Newman healthcare utilisation model was adapted as the framework for this study. ${ }^{15}$ This model is appropriate in explaining critical factors implicated in delayed dental visits by children (healthcare utilisation). The model consists of three factors. First, the predisposing factors which are the social and cultural factors that precede illness. For example, demographics (age, gender, education, occupation), culture, health beliefs, attitude, and knowledge. ${ }^{16}$ Second factor, includes enabling logistical factors such as means to access health services (travel costs, insurance etc.). ${ }^{15}$ Third, is the needs factor, comprised of an individual's perception of the health condition ( severity and associated symptoms). ${ }^{17}$ In terms of this study, the needs factors focused on the parental perception of the child's dental conditions, severity and pain

\section{MATERIALS AND METHODS}

Study design and study setting

A cross sectional survey was conducted at the Medunsa Oral Health Centre (MOHC), a specialized public tertiary oral health facility. Additional facilities included in this study are referral clinics and a hospital in the $\mathrm{MOHC}$ catchment area. (Pretoria North clinic, Boikhutsong clinic, KT Motubatse clinic, Soshanguve clinic 2, Kgabo clinic and Odi Hospital dental clinic). Patients managed at $\mathrm{MOHC}$ pay user fees based on income levels, while all other clinics have no user fees. All the facilities were included in the study.

\section{Sample size}

The sample size was estimated to be 350 parents and child pairs, based on the following reliable assumptions: (i) $30 \%$ of parents delay children's dental visits ${ }^{18}$; (ii) margin of error set at $5 \%$, and precision of $5 \%$. Using the PASS (Power Analysis and Sample Size) version 21.0.2, three hundred and eighteen (318) parent-child pairs were needed to achieve the desired estimated precision with $90 \%$ power. The final sample size of 350 was considered to counteract non-response and missing data. The general equation for this sample size calculation is $n$ $=\left(Z^{2} P Q / D^{2}\right)^{19}$

\section{Study population and sampling}

The study population comprised of guardians or parents who brought their children aged 12 years or younger for dental consultation. Parents of children older than 12 years were excluded. The children reported to the clinics due to referrals from school or clinic or brought by parents due to pain or other dental problems. Proportional samples were recruited for each clinic based of the weighted clinic size, therefore large clinics recruited proportionally more patients than smaller ones. The enrollment process continued until the required sample was reached for each clinic. For consistency, the term parents is used instead of guardians throughout the article.

Data collection

The questionnaire used in this study was adapted from previous studies assessing caregivers' factors associated with late dental visits by children. ${ }^{6-8}$ The tool was translated into Setswana and piloted for content and face validity. The researcher and supervisors evaluated all the questions for relevance, simplicity and clarity. An expert Setswana speaker translated the validated English questionnaire into Setswana. Once completed, the tool was back translated into English by a different language expert. Inconsistencies were resolved between the translators and the researchers. The questionnaires comprised three sections:

(i) Demographic characteristics of parents and children, which measured age, gender and socioeconomic status (education and employment status)

(ii) Sixteen questions assessed parental knowledge, attitudes, and perceptions about child's oral health

(iii) Children's oral health status assessed as part of comprehensive examination on a dental chair. Calibrated clinicians recorded the $\mathrm{dmft}$ and other dental conditions based on the $\mathrm{WHO}$ guidelines

Measurement of delayed dental care for children Delayed dental visit is not well conceptualised, its measurement is at best obscure or unclear. Normatively, any patient who reports for dental care with signs and symptoms has delayed seeking care. However, we wanted to develop a measure that would incorporate existing barriers to care, and the effort to seek care. Delayed dental visit, as a dichotomous variable represented the probability that a child would receive dental treatment after the outcomes of interest had occurred, beyond the specified period. Arbitrary time was set by researcher for treatment of dental pain to be seven days (week) or more. For general dental problems, the duration was set at 1 month or more. Therefore, dental consultation for children beyond the specified times (1 week or after a month), was regarded as delayed dental treatment for dental pain and general dental problems respectively. These variables were computed based on several questions assessed in the study: (i) why did you bring your child to the dental clinic, and (ii) how long have you been aware of the child's problem.

\section{Data analysis}

Data were analysed using SPSS version 23 software. Descriptive statistics included frequencies, measures of central tendency and dispersion. The magnitude of association (odds ratios) were computed for the dependent variable or outcome (delayed dental treatment compared to early treatment) and independent variables: (i) knowledge, attitude and perception of guardians about child's oral health; (ii) demographic variables, and (iii) clinical variable (dmft). The significance level for the statistical analysis was set at $5 \%$.

\section{Ethical Considerations}

Ethical clearance to conduct this study was granted by Sefako Makgatho Health Sciences University Research and Ethics Committee (SMUREC/D/221/2016: PG). The districts and hospital managers in the participating facilities also granted permission. Participants consented to take part in the study and anonymity was ensured throughout the research.

\section{RESULTS}

Demographic profile of parents and children

Of the 350 parent and child pairs in the study, 214 (61.1\%) of children were below 6 years with the mean age of 
$6.31 \pm 2.38$ years and largely female, 223(63.71\%). Most parents 244(72.6\%) were aged between 25-44 years, mean age $36.94 \pm 9.40$, the majority were female $325(90.0 \%)$ unemployed 281(80.3\%) and reached high school 281(80.3).

\begin{tabular}{|c|c|c|}
\hline & Variable & n (\%) \\
\hline \multirow{2}{*}{ Gender (Child) } & Male & 127 (36.3) \\
\hline & Female & 223 (63.7) \\
\hline \multirow{2}{*}{ Gender (Parent) } & Male & $35(10.0)$ \\
\hline & Female & 315 (90.0) \\
\hline \multirow{2}{*}{ Age (Child) } & $1-6$ & 214 (61.1) \\
\hline & $7-12$ & 136 (38.9) \\
\hline \multirow{5}{*}{ Age (Parent) } & $\leq 24$ & 22 (6.3) \\
\hline & $25-34$ & $139(39.7)$ \\
\hline & $35-44$ & 115 (32.9) \\
\hline & $45-55$ & 58 (16.6) \\
\hline & $\geq 55$ & $16(4.5)$ \\
\hline \multirow{2}{*}{ Education } & No formal education & $9(2.6)$ \\
\hline & Up to high school & $272(77.7)$ \\
\hline \multirow{3}{*}{ Employment status } & Diploma/Degree & 69(19.7) \\
\hline & Employed & $69(19.7)$ \\
\hline & Unemployed & 281(80.3) \\
\hline
\end{tabular}

Parental knowledge, attitudes, and perceptions of oral health

Parents' knowledge, attitudes, and perceptions about children's oral health is confirmed in Table 2. Over half of the parents $(52.9 \%)$ indicated that pain was the main reason for bringing their children for dental consultation. Two-thirds of the parents perceived their children's oral health as fair (66.3\%), and $87.7 \%$ recognized bad diet as the cause of dental problems. As many as 52, $6 \%$ of the parents "did nothing" to manage child's dental pain, while $41.1 \%$ "did nothing" to manage a presenting dental condition. In effect, $88 \%$ of parents were inclined to seek immediate healthcare for medical conditions (figure 1) and (62.3\% preferred dental extractions as a means of dealing with dental problems. (Table 2).

Association of parental factors with delayed dental visits for children

Table 3 and 4 show the association between paternal factors and dependent variable (delayed dental visits by children). Differences in education and employment among the parents with respect to time of dental consultation

Figure 1. Conditions for which parents are inclined to professional help for their children

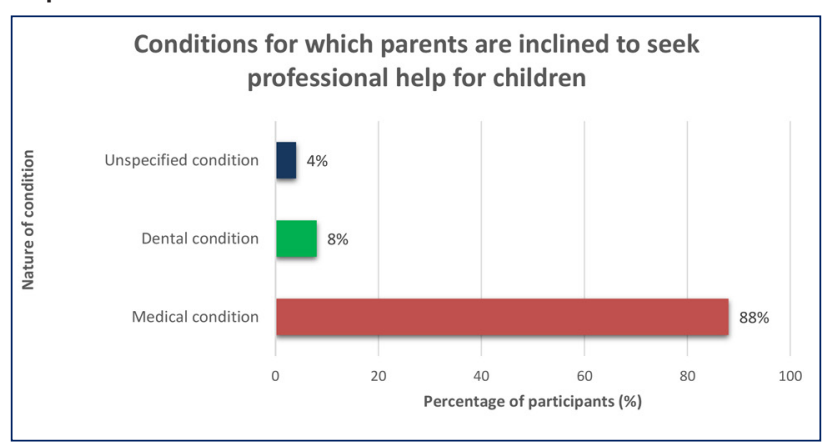

\begin{tabular}{|c|c|}
\hline Variable & $\mathrm{n}(\%)$ \\
\hline \multicolumn{2}{|l|}{ Reason for child's dental consultation } \\
\hline Dental caries & $46(13.1)$ \\
\hline Pain & $185(52.9)$ \\
\hline Checkup or referral & $119(34.0)$ \\
\hline \multicolumn{2}{|c|}{ Perception of child's oral health status } \\
\hline Excellent & $54(15.4)$ \\
\hline Fair & $232(66.3)$ \\
\hline Poor & 64 (18.3) \\
\hline \multicolumn{2}{|l|}{ Causes of oral poor oral conditions } \\
\hline Bad diet & $307(87.7)$ \\
\hline Other causes except diet & $8(2.3)$ \\
\hline I don't know & $35(10)$ \\
\hline \multicolumn{2}{|l|}{ Management of child's dental pain } \\
\hline Home remedies & $83(23.7)$ \\
\hline Medication & $83(23.7)$ \\
\hline Nothing & $184(52.6)$ \\
\hline \multicolumn{2}{|c|}{ Management of child dental conditions } \\
\hline Consult (dentist or traditional healer & $92(26.3)$ \\
\hline Home care (remedies) & $114(32.6)$ \\
\hline Nothing & $144(41.1)$ \\
\hline \multicolumn{2}{|l|}{ Importance of milk teeth } \\
\hline Aesthetics or function & $210(60.0)$ \\
\hline Aesthetics and function & $96(27.4)$ \\
\hline Not Important & $44(12.6)$ \\
\hline \multicolumn{2}{|l|}{ What is the fate of affected milk teeth } \\
\hline Extraction & $218(62.3)$ \\
\hline Save & $67(19.1)$ \\
\hline Don’t know & $65(18.6)$ \\
\hline \multicolumn{2}{|c|}{ When do you abandon home care to consult } \\
\hline When pain persists & $131(37.4)$ \\
\hline When the problem does not resolve & $35(10.0)$ \\
\hline Not answered & $184(52.6)$ \\
\hline
\end{tabular}

for pain and other dental conditions were statistically insignificant. However, parents with tertiary education were 1.82 times more likely to delay dental visits for their children for other dental problems $(p=0.03)$. Similarly, parental mean ages were not statistically significant for visitation times; $p$-values were 0.89 and 0.49 , for those with pain and other dental conditions respectively. For children who consulted with dental pain, the severity of caries (dmft) did not differ significantly between those whose dental visits were delayed and those whose dental consultation was on time, $F(1,348)=0.20, p=0.66$. In the same way, no differences in $\mathrm{dmft}$ scores were reported for children who consulted for dental conditions, $F(1,348)=$ $2.00, p=0.16$. The caries experience among the parents did not have any impact on the timing of dental visits for children.

There was a $93 \%$ and $81 \%$ reduction in delayed dental visit when a child was in pain or had caries, compared to $69 \%$ and $39 \%$ when a child had other dental conditions. Therefore, dental pain and dental caries compared to other dental conditions are significant reasons why parents seek dental treatment for their children without delay. Parents who perceived their children's oral health as excellent or fair were more likely to delay dental treatment. Thus, perception influenced the probability of dental delay, though the findings are statistically insignificant. For those parents who used home remedies and medication 
Table 3. Association of Parent's knowledge and attitude about oral health and delayed dental visit due to pain

Delayed visit vs not delayed

Variable

OR $(95 \% \mathrm{Cl})$

Gender of the parent

Male

Female

Education level of parent

Tertiary education

Up to high school

\section{Employment status of parent}

Employed

Unemployed

Reason for child's dental consultation

Pain

Dental caries

Checkup or referral

0.07 (0.03: 0.16)

$0.19(0.07: 0.56)$ *

1.00

Perception of child's oral health status

Excellent

Fair

Poor

1.14 (0.53: 2.47)

$1.53(0.85: 2.78)$

1.00

Management of child's dental pain

Nothing

1.00

Home remedies + medication

$4.06(2.45: 6.74)$ *

Knowing the Importance of milk teeth

Aesthetics and or function

$0.96(0.47: 1.95)$

Not Important

1.00

What is the fate of affected milk teeth

Don't know

1.00

Extraction

$1.23(0.66: 2.29)$

Save

$0.81(0.37: 1.81)$

Which conditions require urgent medical attention

Acute medical conditions

1.27 (0.52: 3.11)

General medical conditions

0.85 (0.35: 2.05)

Dental condition

1.00

When do you abandon home care to consult

Not applicable

1.00

When pain persists

$0.22(0.13: 0.37)$ *

When the problem does not resolve

$0.39(0.17: 0.89)$ *

*statistically significance

to manage dental pain and other dental conditions, the probability of the delayed dental visit for children is expected to increase four-fold. The odds ratios were, 4.06 (2.45: 6.74) and 3.66 (2.34: 5.71) respectively. Thus, regular use of home remedies and medication exacerbate delayed dental visits for children, irrespective of the problem. Having knowledge about the importance of milk teeth reduced probability of delayed dental visits for pain and other dental conditions. Similarly, for those parents who believed that milk teeth should be saved, there was a $19 \%$ reduction in delayed visits compared to those who did not. On the contrary, the belief that the fate of milk teeth was dental extractions increased the probability of delayed dental visits, ORs $=1.23$ and 2.04 for pain and other dental conditions respectively.

\begin{tabular}{|c|c|}
\hline \multicolumn{2}{|c|}{ Delayed visit vs not delayed } \\
\hline Variable & OR $(95 \% \mathrm{Cl})$ \\
\hline \multicolumn{2}{|l|}{ Gender of the parent } \\
\hline Male & $0.74(0.34: 1.65)$ \\
\hline Female & 1 \\
\hline \multicolumn{2}{|l|}{ Education level of parent } \\
\hline Tertiary education & $1.82(1.06: 3.14)^{\star}$ \\
\hline Up to high school & 1 \\
\hline \multicolumn{2}{|l|}{ Employment status of parent } \\
\hline Employed & 1.04 (0.59: 1.84) \\
\hline Unemployed & 1 \\
\hline \multicolumn{2}{|l|}{ Reason for child's dental consultation } \\
\hline Pain & $0.21(0.13: 0.34)$ * \\
\hline Dental caries & $0.61(0.30: 1.21)$ * \\
\hline Checkup or referral & 1.00 \\
\hline \multicolumn{2}{|c|}{ Perception of child's oral health status } \\
\hline Excellent & $0.92(0.44: 1.90)$ \\
\hline Fair & $0.84(0.48: 1.45)$ \\
\hline Poor & 1.00 \\
\hline \multicolumn{2}{|l|}{ Management of child's dental pain } \\
\hline Nothing & 1.00 \\
\hline Home remedies + medication & $3.66(2.34: 5.71)^{\star}$ \\
\hline \multicolumn{2}{|l|}{ Knowing the Importance of milk teeth } \\
\hline Aesthetics and or function & $0.89(0.47: 1.67)$ \\
\hline Not Important & 1.00 \\
\hline \multicolumn{2}{|l|}{ What is the fate of affected milk teeth } \\
\hline Don't know & 1 \\
\hline Extraction & $2.04(1.16: 3.58)^{\star}$ \\
\hline Save & $1.63(0.82: 3.25)$ \\
\hline \multicolumn{2}{|c|}{ Which conditions require urgent medical attention } \\
\hline Acute medical conditions & 1.19 (0.53: 2.68) \\
\hline General medical conditions & $1.02(0.45: 2.30)$ \\
\hline Dental condition & 1.00 \\
\hline \multicolumn{2}{|c|}{ When do you abandon home care to consult } \\
\hline Not applicable & 1.00 \\
\hline When pain persists & $0.29(0.13: 0.37)^{\star}$ \\
\hline When the problem does not resolve & $0.23(0.10: 0.53)^{\star}$ \\
\hline
\end{tabular}

The probability of delayed dental visits increased by $27 \%$ and $19 \%$ respectively, for parents who considered acute medical conditions (fever, diarrhoea) as requiring urgent attention than dental conditions (pain and other problems). However, general medical conditions in children did not take precedence over dental conditions, especially dental pain, OR 0.85 (0.35: 2.05). Persistent pain and un-resolving dental problems were associated with significant reduced dental visit delays, odds ratios range between 0.22 and 0.39 .

\section{DISCUSSION}

The discussion is based on the three key components of the Anderson and Newman framework namely, the predisposing, enabling and need factors. Critical 
predisposing factors to delayed treatment for children by parents include gender, education and employment status. This study showed that parental gender, level of education and unemployment have no significant impact on dental visits for children. These results differ from published literature, which suggests that females are more likely to seek care for all members of the family. ${ }^{20}$ Similarly, literature shows that parental educational level significantly influenced the utilization of services and children's dental visits. ${ }^{21}$ Parents with low educational achievements were likely to delay or miss their children's dental visits. ${ }^{22}$ Therefore, low family income and high costs of dental care could be contributing to this delay, as well as failure to attend dental appointments. ${ }^{23}$ This study could not corroborate the critical role of socio-economic status on delayed dental visits by children. The study findings failed to demonstrate that parents with better socio-economic fortunes, that is education and employment, could access dental care for their children timeously. For these parents their socioeconomic standing was relatively inconsequential in ushering meaningful advantage or opportunity to reduce delayed dental visits for their children.

We hypothesise from definition that, delayed dental visits, are indicative of unplanned, random, episodic and reactive engagement with the oral health services. Delayed dental visits for children, suggests that parents may lack the resources and opportunity to access even free public oral health services regularly and consistently. We contend that in poor communities, this phenomenon is prevalent; most parents tend to attend to physiological needs, like food and shelter ahead of health and safety. Additionally, limited financial resources and time are directed towards more critical areas than dental services, resulting in delayed dental care.

The failure to demonstrate the association of SES and delayed dental visits is attributable to the study design and measurement. Cross-sectional studies cannot demonstrate the changes in services utilization (delays) over time and across different strata. There we were unable to show the long-term effects employment status and education dental visitations. We used employment and education as proxies for socioeconomic status instead of health index $(\mathrm{HI})$. This index is difficult to compute and ascertain in our settings as it combines data on durable assets, housing characteristics and access to services. These limitations might account for the lack of empirical significant association between SES and outcomes of interest.

According to Andersen ${ }^{13}$, utilizations of oral health services is also influenced by the perceptions of one's oral conditions. In this case, parental perceptions and attitude towards their children's oral health will affect the utilization of oral health services. Dental pain and caries experience in children prompted parents to bring children for dental consultation, without delay. There was a $93 \%$ and $81 \%$ reduction in delayed visitations for children respectively due to these conditions. However, most parents still opted for selfmedication $(\mathrm{OR}=4.06)$ and only abandoned home care when the pain persisted $(\mathrm{OR}=0.22)$ or condition did not resolve $(O R=0.39)$. Compared to similar studies, parents sought dental treatment when the children's needs were severe and once affordable options have been explored. ${ }^{20}$ This oral health seeking behaviour underpins the role of enabling factors such income and education in dental visitations. Income is a significant enabling factor and barrier to access dental care. ${ }^{24}$ The poor face exorbitant travel and dental service costs in spite of their catastrophic state of living. ${ }^{20,25}$ Unsurprisingly, parents considered acute medical conditions as urgent compared to dental pain and conditions $(O R=1.27)$. Dental care is not prioritised in poor settings; it is often perceived as additional or optional treatment except for dental extractions, which are deemed necessary and ultimate.${ }^{26}$

Timeous dental visits for children are crucial in ensuring that possible clinical and socio-economic consequences of untreated dental conditions are minimised or completely averted. Untreated oral disease such as caries, worsens with time and eventually requires more serious and expensive treatment to resolve. Early contact with dental professionals affords children the opportunity to access dental care, reduce dental phobia, improve compliance and leads to good oral health outcomes. ${ }^{27,28}$ Parental factors such as poverty, unemployment, education and abject inequality remain serious barriers for poor children to access dental services. ${ }^{28,29}$ Delays in the utilization of regular preventative, promotive and curative services among the poor will worsen oral health outcomes.

\section{CONCLUSION}

The results of our study show that the parental attitude and perception; dental pain and caries in children reduce delayed dental visits. The use of home remedies and selfmediation contribute to delayed dental visits. similarly, unemployment, poor education and female gender may exacerbate delayed dental consultations for children.

\section{References}

1. Douglass JM, Douglass AB, Silk HJ. A practical guide to infant oral health. Am Fam Physician. 2004;70(11):21132120.

2. Yadav K, Prakash S. Dental caries: a review. Asian Journal of Biomedical and Pharmaceutical Sciences. 2016;6(53):1-7.

3. Van Wyk P, Louw A, Du Plessis J. Caries status and treatment needs in South Africa: report of the 19992002 National Children's Oral Health Survey. SADJ. 2004;59(6):240-242.

4. Casamassimo PS, Thikkurissy S, Edelstein BL, Maiorini E. Beyond the dmft: the human and economic cost of early childhood caries. The Journal of the American Dental Association. 2009;140(6):650-657.

5. Källestål C, Norlund A, SoĖder B, et al. Economic evaluation of dental caries prevention: a systematic review. Acta odontologica Scandinavica. 2003;61(6):341-346.

6. Bradbury-Jones C, Innes N, Evans D, Ballantyne F, Taylor J. Dental neglect as a marker of broader neglect: a qualitative investigation of public health nurses' assessments of oral health in preschool children. BMC Public Health. 2013;13:370.

7. Sharma I, Chauhan P, Galhotra V, Duhan H, Kaur M, Sharma S. Dental Neglect among Children And Their Parents In District Panchkula. International Healthcare Research Journal. 2019:265-269.

8. Chhabra N, Chhabra A. Parental knowledge, attitudes and cultural beliefs regarding oral health and dental care of preschool. European Archives of Paediatric Dentistry. 2012;13(2):76-82. 
9. Tickle M, Blinkhorn A, Milsom K. The occurrence of dental pain and extractions over a 3-year period in a cohort of children aged 3-6 years. Journal of public health dentistry. 2008;68(2):63-69.

10. Bomhof-Roordink $H$, Gärtner FR, Stiggelbout AM, Pieterse $\mathrm{AH}$. Key components of shared decision making models: a systematic review. BMJ Open. 2019;9(12):e031763.

11. Green EC, Murphy EM, Gryboski K. The health belief model. The Wiley Encyclopedia of Health Psychology. 2020:211-214.

12. Eze P. An analytical model of demand for hospital inpatient care. International Journal of Social Sciences Perspectives. 2018;2(1):80-86.

13. Anderson J. Health services utilization: framework and review. Health services research. 1973;8(3):184.

14. Andersen RM, Yu H, Wyn R, Davidson PL, Brown ER, Teleki S. Access to medical care for low-income persons: how do communities make a difference? Medical care research and review. 2002;59(4):384411.

15. Babitsch B, Gohl D, von Lengerke T. Re-revisiting Andersen's Behavioral Model of Health Services Use: a systematic review of studies from 1998-2011. Psychosoc Med. 2012;9:Doc11-Doc11.

16. Parslow R, Jorm A, Christensen $H$, Jacomb P. Factors associated with young adults' obtaining general practitioner services. Australian Health Review. 2002;25(6):109-118.

17. Broyles RW, McAuley WJ, Baird-Holmes D. The medically vulnerable: their health risks, health status, and use of physician care. Journal of health care for the poor and underserved. 1999;10(2):186-200.

18. Afeef M, Felemban N, Alhazmi N, Natto ZS. Factors associated with a late visit to dentists by children: A cross-sectional community-based study in KSA. Journal of Taibah University Medical Sciences. 2021;16(4):513-520.

19. Kothari C. research methodology methods and techniques by CR Kothari. Published by New Age International (P) Ltd, Publishers. 2017;91.

20. Uguru N, Onwujekwe O, Uguru C, Ogu U, Okwuosa C, Okeke C. Oral health-seeking behavior among different population groups in Enugu Nigeria. PLoS One. 2021;16(2):e0246164.

21. Shetty N, Mala K, Suprabha BS, Shenoy R. Association of level of education and utilization of restorative dental care among rural women in India: Cross-sectional study. Indian J Dent Res. 2017;28(6):642-645.

22. 22. Locker D, Maggirias J, Quiñonez C. Income, dental insurance coverage, and financial barriers to dental care among Canadian adults. J Public Health Dent. 2011;71(4):327-334.

23. Listl S. Cost-related dental non-attendance in older adulthood: evidence from eleven European countries and Israel. Gerodontology. 2016;33(2):253-259.

24. Vujicic M, Buchmueller T, Klein R. Dental care presents the highest level of financial barriers, compared to other types of health care services. Health affairs. 2016;35(12):2176-2182.

25. Willink A, Schoen C, Davis K. Dental care and Medicare beneficiaries: access gaps, cost burdens, and policy options. Health Affairs. 2016;35(12):22412248.
26. Mertz EA. The dental-medical divide. Health Affairs. 2016;35(12):2168-2175.

27. Beil H, Rozier RG, Preisser JS, Stearns SC, Lee JY. Effects of early dental office visits on dental caries experience. Am J Public Health. 2014;104(10):19791985.

28. Bersell $\mathrm{CH}$. Access to oral health care: a national crisis and call for reform. American Dental Hygienists' Association. 2017;91(1):6-14.

29. Sohn W, Ismail A, Amaya A, Lepkowski J. Determinants of dental care visits among low-income AfricanAmerican children. The Journal of the American Dental Association. 2007;138(3):309-318. 